\title{
SPINAL LESIONS IN BATTERED BABIES
}

\author{
John C. Cullen, Auckland, New Zealand \\ From the Orthopaedic Department, Medical School, Auckland
}

\begin{abstract}
The case histories of five young children are presented to demonstrate the radiological appearances of trauma to the spine thought to be the result of maltreatment by either parent or guardian. Four of the children were admitted to hospital within a period of three years, all being under the age of two years.
\end{abstract}

Multiple trauma in infants with no history of injury was first recorded in 1946 by Caffey, who reported six cases of fractures of the limbs associated with chronic subdural haematoma. In a later paper he described the typical radiological findings and again pointed out the usual absence of a history of trauma and the difficulty in establishing the diagnosis despite characteristic appearances (Caffey 1957). Kempe, Silverman, Steele, Droegemueller and Silver (1962) first used the term "the battered child syndrome" and reported a number of cases. A slight modification of this term has led to the now accepted phrase "battered baby syndrome".

In the three years from January 1971 to January 1974, four children with a spinal injury, probably the result of trauma inflicted by either parent or guardian, were admitted to the Auckland Public Hospital. A fifth child was admitted to the Middlemore Hospital, Auckland, in 1967.

\section{CASE REPORTS}

Case 1-This boy was born in February 1967 and was first admitted at the age of nine months with bruising of the face. A radiograph of the skull showed the sutures a little wider than usual, suggesting raised intracranial pressure. A month later he was admitted for further assessment because of extensive superficial bruising. A year previously a sibling had died at the age of two years; no satisfactory explanation had been given for this death. The possibility of child abuse was now raised, but radiographs of the spine, pelvis and long bones were reported normal.

At the age of fourteen months he was readmitted with a fracture of the lower end of the right femur, and again two months later because of weakness of the legs. At this time the baby's foster mother was also in hospital, for psychiatric treatment.

On examination there was an upper thoracic kyphos and a general increase of tone in the muscles of both legs. Sensibility in the lower limbs was normal and the reflexes were brisk. Radiographs showed fractures of the seventh and eighth ribs anteriorly on the left side. The skull appeared normal but the right femur showed a healing fracture. The radiograph of the spine showed an acute kyphos at the level of the T.3 apparently due to compression or destruction of the body of the vertebra (Fig. 1). On reviewing the earlier films it was found that this abnormality was present at the time of the second admission six months previously. Further radiographs and tomograms showed that the compressed body of the T.3 was displaced posteriorly in relationship to the vertebra above and below. It was felt that these changes were due to either trauma or infection.

A course of antibiotics was started and continued for some months. The environment of the foster home was investigated by the Department of Social Welfare, and because it was far from satisfactory the child was transferred to another foster home. When the child was last seen four years after

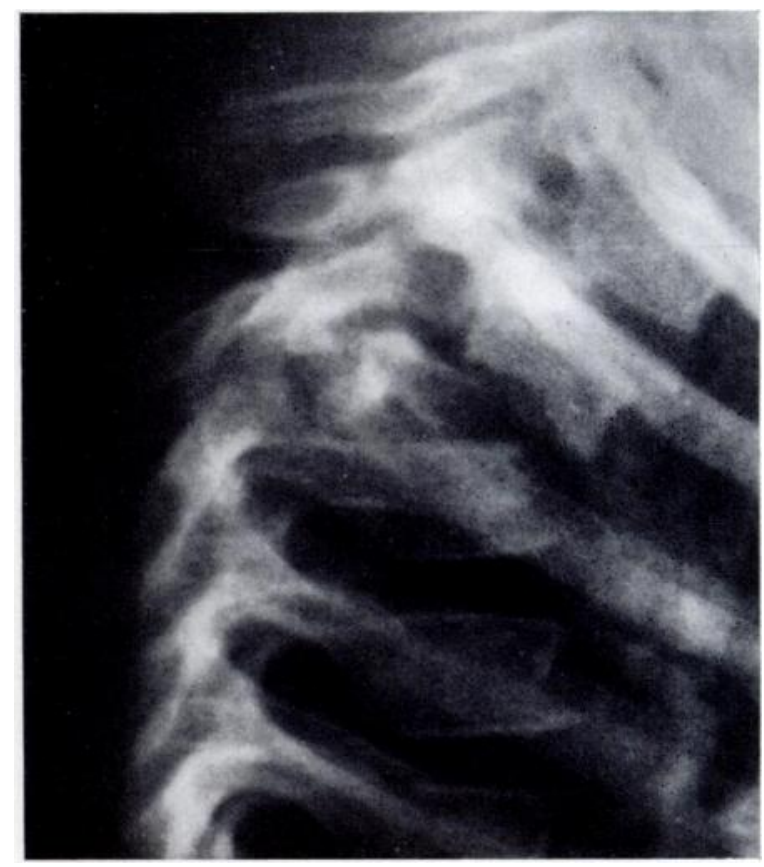

FIG. 1

Case 1-A radiograph taken in July 1967.

his original admission the tone in the right leg was still increased but the reflexes were symmetrical.

Case 2-This boy was born in June 1970 and was first admitted at the age of fourteen months. His mother said that she had found him unconscious on the kitchen floor. This child had an entirely normal twin brother. On examination he was drowsy and had a left hemiparesis. Bruising on the right side of the head extended backwards from the frontal region. There was a history of many falls and he had been seen at another hospital six months previously for a fracture of the left arm. Radiographs of the skull showed a fracture of the vault and an echo encephalogram demonstrated a 1-centimetre shift of the midline structures to the left. A right-sided subdural haematoma was later evacuated.

John C. Cullen, F.R.C.S., Department of Orthopaedic Surgery, Auckland Hospital, Park Road, Auckland, New Zealand. 


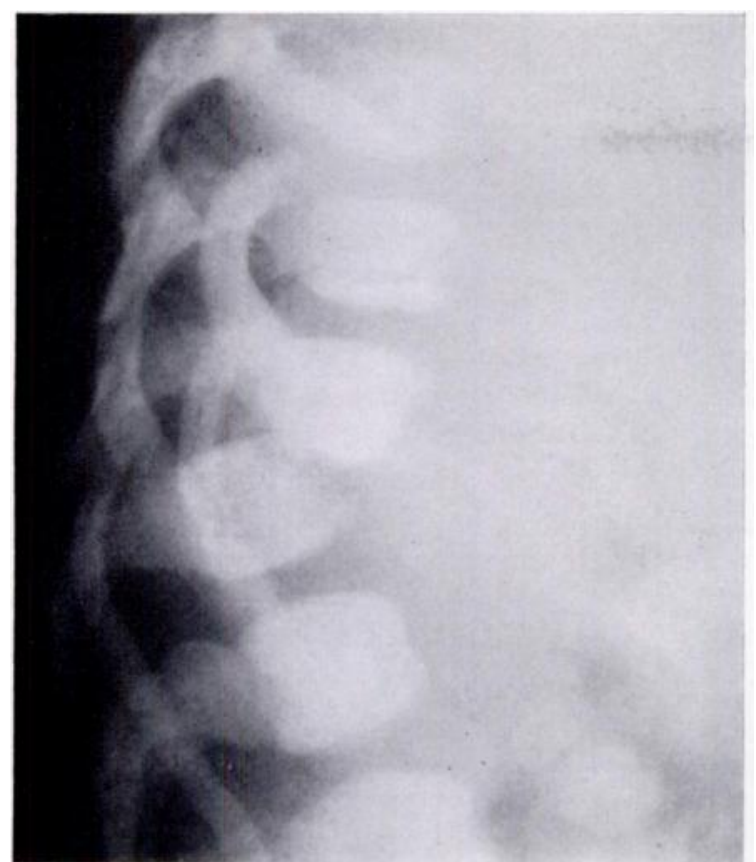

FiG. 2

Case 2-A radiograph taken in August 1971.

Ten days after admission it was noticed that the child had a bony prominence in the upper lumbar area. A radiograph revealed a fracture dislocation of T.12 on L.1 with T.12 displaced forward about 1.5 centimetres (Fig. 2). There was no evidence of cord compression. Four months after his admission, normal sensibility was present over both legs but he was not walking. When last seen at the age of twenty months the kyphos was still obvious and he was starting to walk with support.

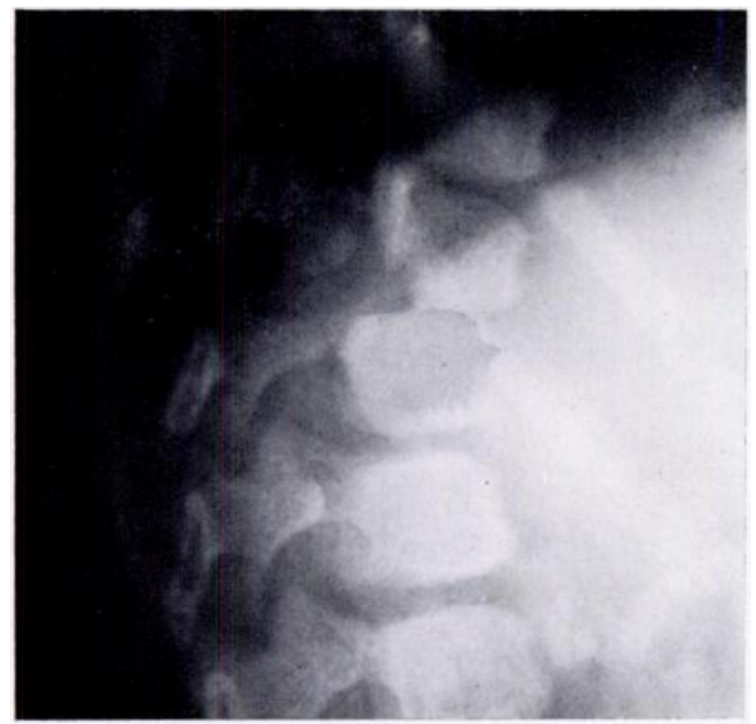

FiG. 3

Case 3-A radiograph taken in December 1972.

Case 3-This boy was born in May 1971 and first attended the outpatient department at the age of sixteen months. He was said to have fallen from a high chair and a radiograph of the skull showed a fracture of the left parietal bone. Three months later he was admitted at the request of the Child

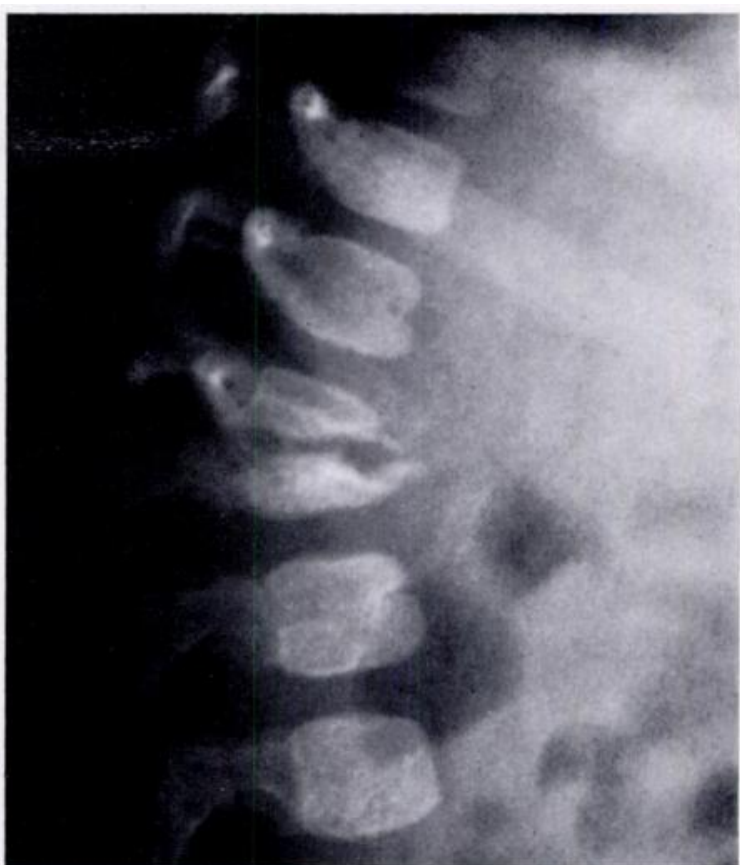

FIG. 4

Case 4-A radiograph taken in February 1972.

Welfare Department. Since the age of six months he had been cared for by foster parents and maltreatment was suspected.

On examination there was a vertical scar over the right eyebrow, a large haematoma of the right thigh, a bruise of the right ankle and a marked thoraco-lumbar kyphos. Radiographs showed a fissure fracture of the left parietal bone, irregularity of the metaphysis of the upper end of the left humerus, and recent fractures of the lower end of the left radius and ulna. The left femur showed new bone formation around the shaft and partial separation of the upper epiphysis. The thoracic spine showed a subluxation of T.11 on T.12 (Fig. 3). There were no neurological signs. A new foster home was arranged and the child was discharged four months after admission.

Case 4-This girl was admitted twice to hospital with bronchopneumonia at four and sixteen months. Radiographs of the spine taken during the second admission showed a kyphosis at the thoraco-lumbar junction. There was a marked reduction in height of the bodies of T.12 and L.1 with narrowing of the intervening disc space (Fig. 4). The inferior aspect of the body of T.12 and the superior aspect of the L.1 were deficient. There was some bone sclerosis of T.12 inferiorly. The cause of the abnormality was uncertain but injury was thought the most likely. A skeletal survey showed no other bony injury.

The medical social worker later found that the home situation had been unsatisfactory, the child having been looked after by her grandmother. While the grandmother was on holiday the child was returned to her mother and evidence of maltreatment during this period was eventually obtained. This child is now living with a foster mother.

Case 5-This boy was born in January 1970 and was admitted to hospital at the age of two years because of "failure to thrive". On admission radiographs showed a recent fracture of the left parietal bone and old fractures of the right capitellum and lower end of left humerus. He was readmitted a year later at the age of three, because of failure to gain weight and retarded speech. This child was the second of four children; 
two others in the family had impaired mental and physical development.

On examination there was bruising of both arms and forearms. A skeletal survey showed loss of anterior height of the bodies of L.1 and L.2, with disruption of their inferior

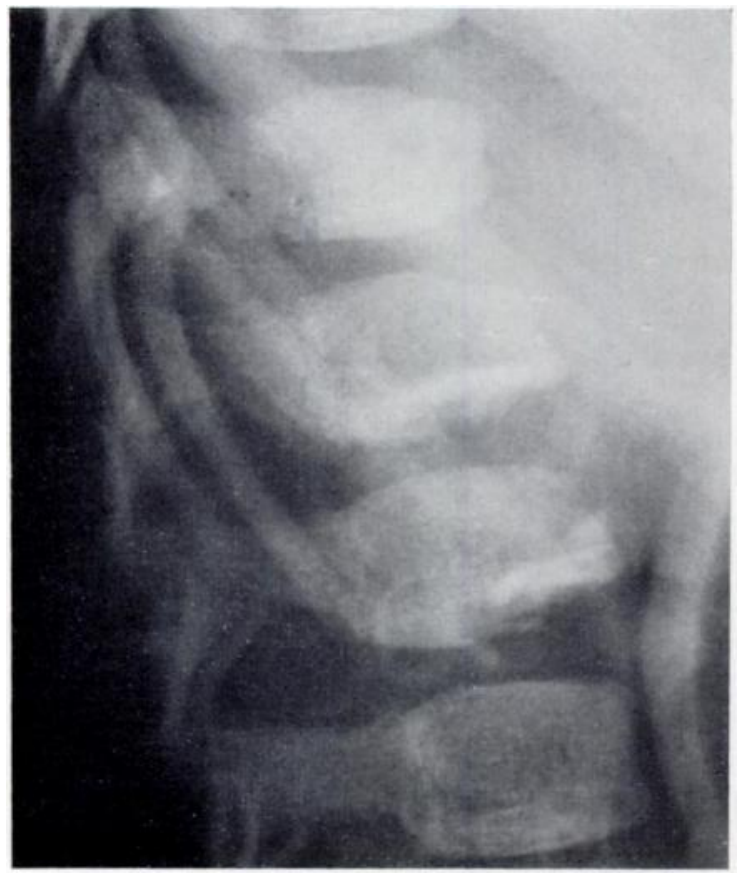

FIG. 5

Case 5-A radiograph taken in January 1974.

surfaces and sclerosis anteriorly (Fig. 5). The appearances were thought to be from trauma. Investigations have not revealed any abnormality of bone which would make this child more susceptible to injury. There has been no direct evidence of maltreatment, but neither has there been any satisfactory explanation for the numerous bone injuries.

\section{DISCUSSION}

Five cases of lesions of the spine in young children are reported; it was suspected in each case that trauma had been inflicted by the parent or guardian. Three of these children were admitted to the Auckland Public Hospital over a period of three years. Twenty-two battered children, seventeen under two years of age, were admitted to the same hospital over a different three-year period and were reviewed by Thomson (1973). Seventeen had fractures of one or more long bones and eight had fractures of the skull; spinal injury was not recorded. A comparison with his series suggests that of those children admitted to hospital with multiple trauma inflicted by parent or guardian, a significant number will have a spinal injury. The absence of neurological signs, which is usual, or of obvious deformity, may allow the spinal lesion to pass unrecognised.

The children admitted to hospital form only a small proportion of those injured by parents or guardian. For the year 1967 the New Zealand Department of Social Welfare reported 419 incidents of child abuse involving 363 children out of a population of three million (Ferguson 1972).

In the absence of evidence of maltreatment it may be difficult on radiological evidence alone to attribute lesions of the long bones to trauma. Caffey (1957), however, would disagree. With multiple lesions including metaphysial irregularities and circumferential thickening of the shafts, he feels that multiple trauma can be distinguished from other skeletal disorders of infants such as scurvy, hyperostosis, rickets, hypervitaminosis $\mathrm{A}$ and certain bone infections. In our first case the original diagnosis was osteomyelitis and the child was treated for many months with antibiotics.

In the five cases presented the level of spinal injury varied. No histories were available as to the mechanisms of injury, but the radiological appearances suggest hyperflexion. In each child there were associated injuries either of the limbs or of the skull. This emphasises the importance of a full radiological survey in children suspected of being maltreated by a parent or guardian.

\section{REFERENCES}

Caffey, J. (1946) Multiple fractures in the long bones of infants suffering from chronic subdural hematoma. American Journal of Roentgenology and Radium Therapy, 56, 163-173.

Caffey, J. (1957) Some traumatic lesions in growing bones other than fractures and dislocations: clinical and radiological features. British Journal of Radiology, 30, 225-238.

Ferguson, D. M., Fleming, J., and O'Neill, D. P. (1972) Child Abuse in New Zealand, p. 44. Wellington: Government Printer.

Kempe, C. H., Silverman, F. N., Steele, B. F., Droegemueller, W., and Silver, H. K. (1962) The battered-child syndrome. Journal of the American Medical Association, 181, 17-24.

Thomson, A. N. (1973) Personal communication. 